\title{
Drying kinetics of black turmeric (Curcuma caesia) with optimal controller assisted low cost solar dryer
}

\author{
1,2, ${ }^{*}$ Kondareddy, R., ${ }^{2}$ Sivakumaran, N. and ${ }^{3}$ Nayak, P.K. \\ ${ }^{1}$ Department of Instrumentation Engineering, Central Institute of Technology, Kokrajhar, Assam-783370, \\ India \\ ${ }^{2}$ Department of Instrumentation and Control Engineering, National Institute of Technology, Tiruchirappalli, \\ 620015, Tamil Nadu, India \\ ${ }^{3}$ Department of Food Engineering and Technology, Central Institute of Technology, Kokrajhar, Assam- \\ 783370, India
}

\begin{abstract}
Article history:
Received: 4 November 2018

Received in revised form: 28

January 2019

Accepted: 5 February 2019

Available Online: 9 February 2019
\end{abstract}

Keywords:

Black turmeric,

PI Controller,

Drying kinetics,

Low-cost dryer

DOI:

https://doi.org/10.26656/fr.2017.3(4).139

\section{Introduction}

Curcuma caesia Roxb. (Black turmeric or black zedoary) is a perennial herb with bluish-black rhizome native to North-East and Central India (Devi et al., 2015; Lakshmi et al., 2018). It contains a very good percentage of curcumin which possesses many curative properties among all the Curcuma or turmeric species. It is recognized as a medicinal herb to possess with various properties such as anti-fungal activity (Banerjee and Nigam, 1976), anti-asthmatic activity (Arulmozhi et al., 2006), antioxidant activity (Mangla et al., 2010; Lakshmi et al., 2018), anxiolytic and CNS depressant activity (Karmakar et al., 2011) and anti-bacterial activity (Rajamma et al., 2012). The rhizomes of the plant are aromatic in nature. The inner part of the rhizome is bluish-black in color and emits a characteristic sweet smell, due to the presence of essential oil (Pandey and Chowdhury, 2003). The higher moisture content (75$79 \%$ ) of black turmeric renders them perishable and seasonal availability limits their utilization all-round the year. Hence, suitable preservation techniques should be developed to extend the shelf life of black turmeric.
Many food preservation methods can be adopted for storage like canning, freezing and controlled atmosphere storage but all these methods are expensive (Kalra et al., 1983).

Drying is the most widely employed method for preserving food materials, which is based on the reduction of the water activity values through moisture removal to achieve physicochemical and microbiological stability (Yaldiz et al., 2001; Maskan et al., 2002; Moreira et al., 2008). Sun drying is one of the oldest drying methods followed in many countries, especially by individual households and small-scale enterprises. Though the method of sun drying is inexpensive, the products may be spoiled due to adverse weather conditions and may also get contaminated with dust, insects and their excreta. Further, the process is timeconsuming, offers non-uniform drying and requires a larger surface area. The product is also vulnerable to absorb moisture leading to reduced quality (Chavda and Kumar, 2009; Rathore and Panwar, 2011). Open sun drying (OSD) is still widely used in many tropical and subtropical countries as it is the cheapest method. For 
turmeric, the common practice in India is to dry it under open solar drying. However, the quality of the dried products in the open sun drying gets affected due to rodents, sudden rain, improper heating, etc. (Sengar, 2018). This can be overcome by introducing solar drying technology.

In solar drying, solar-energy is used as either the sole source of the required heat or as a supplemental source. The air flow can be generated by either natural or forced convection. The heating procedure could involve the passage of preheated air through the product or by directly exposing the product to solar radiation or a combination of both (Ekechukwu, 1989). Utilization of solar energy for drying is advantageous as it is a free, renewable and abundantly available. It is also an environment-friendly and economically viable source which makes it to be acceptable by the rural farmers (Basunia and Abe, 2001), where the electric supply is either scarce or irregular. Studies conducted on solar drying have proved that it is a good substitute for sun drying for the production of high-quality dried products (Saleh and Badran, 2009). Most of the researcher reported studies on solar drying of various agricultural products such as chilli, cauliflower, grapes, mint, turmeric, pepper, apricot and tomato etc. Black turmeric is largely produce in the north-eastern part of India. Further, it is observed that there is no study reported on the drying kinetics of high-value agriculture products such as black turmeric. For the first time the author reporting the open sun and solar drying models for black turmeric.

\section{Materials and methods}

The drying chamber and collector were design, developed with the help of locally available, biologically degradable, low-cost materials (plywood, sawdust, thermocol, cotton, stainless steel mesh, wooden skewers, clear glass, galvanized iron sheet) and whole setup was installed in the department of Instrumentation engineering, Central Institute of Technology, Kokrajhar, Assam, India. The trials were carried out in the month of March-April 2017 under the metrological conditions of Central Institute of Technology, Kokrajhar (26 $24^{\prime} \mathrm{N} 90^{\circ}$ $16^{\prime} \mathrm{E} / 26.4^{\circ} \mathrm{N} 90.27^{\circ} \mathrm{E}$ coordinates and time zone IST (UTC +5:30).

\subsection{Sample preparation for drying}

Black turmeric was collected from a fruit vendor near the Central Institute of Technology, Kokrajhar, Assam, India. Freshness, Color, size, level of maturity and absence of any mechanical damage were used as selection criteria. The rhizomes were washed thoroughly, and the surface water was wiped with a clean tissue paper. The samples were spread uniformly on the trays in a single layer. Initial moisture content was measured by hot air oven (IIC, Model: HA-11, Kolkata) method (Rangana, 2005). The samples were then dried in two different drying system i.e., Sun and Solar. In each experiment, a material density of $2.5 \mathrm{~kg} / \mathrm{m}^{2}$ was used irrespective of the method.

\subsection{Experimental set up}

The schematic of the indirect type solar dryer is shown in Figure 1. The system consists of a collector $(1520 \times 760 \times 180 \mathrm{~mm})$, a transparent plenum chamber $(1220 \times 760 \times 450 \mathrm{~mm})$ with 4 trays and a blower with a capacity of $20 \mathrm{~kg}$. Flat plate collector is used since it is easy to fabricate and also economical. The collector is made up of GI sheet and copper pipe as it is a good conductor and economical. It was painted black to increase the absorption of heat (Queiroz et al., 2011) and a glass of thickness $5 \mathrm{~mm}$ was used (Sukhatme and Sukhatme, 1996). The drying chamber was made of mild steel. Hot air entering from one side and as well as a glass top cover allows the direct sun radiation to pass into the drying chamber. The glass top was provided for an additional drying effect. A centrifugal blower was used for supplying the air. A gate valve was used to control the mass flow rate of air. To prepare drying chamber insulating materials like plywood, sawdust, cotton and thermocol were chosen as it is a good insulator as well as environmentally friendly. In addition, to reduce the heat loss by radiation and to avoid moisture absorption by wood, aluminium foil is wrapped on the inside of the chamber. Food grade stainless steel mesh for the all the four trays was selected for drying of black turmeric. Finally, all these components are fitted in a MS Iron made stand for easy handling and relocating purposes (Lakshmi et al., 2018). The side cover was fixed to the drying chamber using hinges and was lifted up in order to place the samples in the solar dryer.

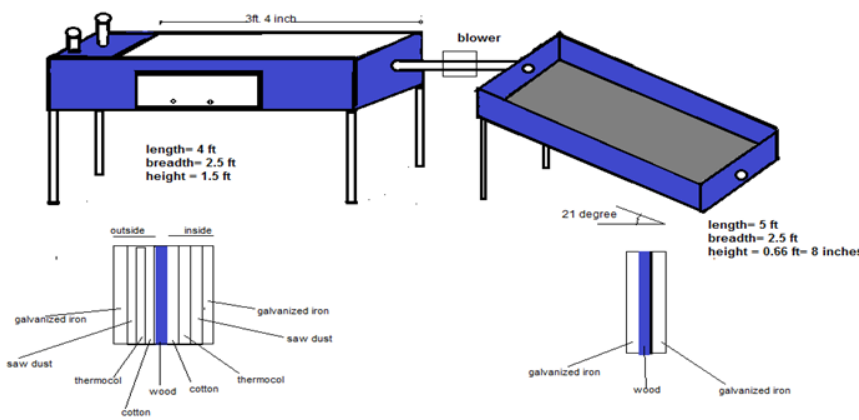

Figure 1. Schematic diagram of solar dryer

The dryer was installed in the top floor of the IE Department as this place was free of shade, particularly for the period of drying from 8 am to $4 \mathrm{pm}$. A digital weighing balance (Denver, Germany) was used to record 
the weight of the sample. Dryer was shut down during the night, and the experimentation was getting resumed the next day at $8 \mathrm{am}$.

\subsubsection{Instrumentation}

A Proportional Integral (PI) controller was implemented to the solar dryer to control the air pump (flow rate of $0.5,1$ and $2 \mathrm{~m} / \mathrm{s}$ ) as a manipulated variable to achieve desired value and to reduce the effect of dead time. A PID controller is applied on this kind of the systems time lagging systems, the derivative part is mostly switched off, and only PI control was used (Hägglund, 1996; Yurkevich and Naidu, 2012). Proportional Integral (PI) controllers are fast and very accurate to reach control objectives it combines the advantages of integral control for zero steady-state error and with proportional control to increase the speed of the transient response (O'Dwyer, 2006; Puglisi et al., 2015). So Proportional Integral (PI) controller was implemented to the solar dryer to study its effect on drying chamber temperature.

A moisture removal monitoring system was also introduced in the drying chamber to remove the moisture from the sample (Dai et al., 2015). The measuring of moisture content in materials is of such prominence in so many fields that a varied of devices and analytical methods in use. The traditional method for measuring moisture content in solids and non-volatile liquids is thermal gravimetric. In a thermal gravimetric system, a sample of the material is sensibly weighed and after the material is dried by the application of heat then reweighed after drying. Any difference in weight generally reduced is indicative of the moisture content removed from the sample (Raisanen et al., 1979). The drying process may be simple exposure to ambient air or in some cases, a hot air driven in solar dryers have been used. The removal of moisture in the testing sample is measured in terms of weight loss, as it is direct and accurate measuring for time-varying parameters. Since the amount of moisture removed from the drying chamber of the solar dryer is not possible to measure directly so it is being measured in terms of weight.
2.3 Drying analysis and evaluation of thin layer drying models

The drying characteristic curves were plotted after analyzing the experimental data. The moisture content was converted to moisture ratio (MR) using the following equation.

$$
M R=\frac{\left(M_{t}-M_{e}\right)}{\left(M_{0}-M_{e}\right)}
$$

Where, $\mathrm{M}_{0}$ is the moisture content, $\mathrm{kg}$ water $/ \mathrm{kg}$ dry matter at beginning of the drying; $M_{e}$ is the moisture content, $\mathrm{kg}$ water $/ \mathrm{kg}$ dry matter when the equilibrium is reached; and $\mathrm{M}_{\mathrm{t}}$ is the moisture content, $\mathrm{kg}$ water $/ \mathrm{kg}$ dry matter at time $\mathrm{t}$,

As the relative humidity of the drying air fluctuated continuously, $\mathrm{M}_{\mathrm{e}}$ was assumed to be negligible and the expression was reduced to:

$$
M R=\frac{\left(M_{t}\right)}{\left(M_{0}\right)}
$$

Mathematical modeling was carried out to describe the drying curve equation of black turmeric and to determine the parameters of the thin layer drying models by fitting experimental data to the model equation. Nine different commonly used models are given in Table 1 and taken into account for specifying the most adequate model in thin layer drying of black turmeric. The nonlinear regression analysis was performed using the statistical analytical tool SAS (Mumbai, India). Although the coefficient of determination $\left(\mathrm{R}^{2}\right)$ was one of the principal criteria for selecting the best model to describe thin-layer drying of the turmeric, the reduced chi-square $\left(\chi^{2}\right)$ was also included to evaluate the goodness of fit of the models (Equations 3 and 4). The lower chi-square $\left(\chi^{2}\right)$ and the higher $\mathrm{R}^{2}$ values, were chosen as the basis of goodness of fit (Midilli and Kucuk, 2003; Akpinar, 2006).

$$
\begin{aligned}
R^{2} & =\frac{\sum_{i=1}^{N}\left(M R_{\text {pre }, i}-M R_{\text {exp,avg }}\right) 2}{\sum_{i=1}^{N}\left(M R_{\text {exp }, ~}-M R_{\text {exp }, a v g}\right) 2} \\
x^{2} & =\frac{\sum_{i=1}^{n}\left(M R_{\text {exp }, i}-M R_{\text {pre }, i}\right) 2}{N-n}
\end{aligned}
$$

Where $\mathrm{MR}_{\text {exp, } \mathrm{i}}$ is the $i$ th experimentally observed moisture ratio; $\mathrm{MR}_{\mathrm{pre}, \mathrm{i}}$ the $i$ th predicted moisture ratio; $\mathrm{MR}_{\text {exp }}$, avg is the average experimental moisture ratio; $\mathrm{N}$ the number of observations and; $\mathrm{n}$ is the number of constants (Sarsavadia et al., 1999). The drying curve for

Table 1. Mathematical models used to describe thin layer drying

\begin{tabular}{rlll}
\hline SN & \multicolumn{1}{c}{ Model Name } & \multicolumn{1}{c}{ Model } & \multicolumn{1}{c}{ References } \\
\hline 1 & Lewis & $M R=\exp (-k t)$ & Kabganian et al. (2002) \\
2 & Page & $M R=\exp \left(-k t^{n}\right)$ & Page (1949); Kabganian et al. (2002); \\
3 & Modified Page & $M R=\exp [-(k t)]^{n}$ & Yaldyz and Ertekyn, (2001); Midilli et al. (2002) \\
4 & Henderson and Pabis & MR $=\mathrm{aexp}(-\mathrm{kt})+(1-\mathrm{a}) \exp (-\mathrm{kt})$ & Demir et al. (2004) \\
5 & Two-term exponential & MR $=\mathrm{aexp}(-\mathrm{kt})+(1-\mathrm{a}) \exp (-\mathrm{kt})$ & Sharaf-Eldeen et al. (1980) \\
\hline
\end{tabular}


each experiment was obtained by plotting the dimensionless moisture ratio of the sample versus the drying time. Modeling the drying of different agricultural products often requires statistical methods of regression and correlation analysis. Linear and non-linear regression models are important tools to find the relationship between different variables, especially, for which no established empirical relationship exists. In this study, the relationships of the constants of the best suitable model with the drying air temperature were also determined by multiple regression technique.

\subsection{Quality analysis}

\subsubsection{Color analysis}

Color of fresh and dried black turmeric slices (dried in both solar dryer and in open sun drying) were measured in terms of the $\mathrm{L}^{*}, \mathrm{a}^{*}$ and $\mathrm{b}^{*}$ values using a Hunter lab Colorimeter (D25 LT, Hunter lab, USA) according to the methods followed by Nayak et al. (2017).

\subsubsection{DPPH radical scavenging activity}

Free radical scavenging activity was determined with a DPPH radical assay, performed according to the modified method followed by Babuskin et al. (2014). Briefly, $100 \mu \mathrm{M}$ of DPPH in ethanol was prepared and 1 $\mathrm{ml}$ of this solution was added to a test sample $(4 \mathrm{~mL})$. The reaction mixture was shaken well and incubated for 30 mins at room temperature. The absorbance of the resulting solution was read at $517 \mathrm{~nm}$ using a UV-Vis spectrophotometer (Lambda 25 UV-VIS, Perkin Elmer, Ohio, USA) against a blank and DPPH radical scavenging activity was expressed as $\mu$ mol of Trolox equivalents (TE) g sample from a standard curve developed with Trolox. All determinations were performed in triplicate. Measurements were performed in triplicate.

\subsubsection{Total phenolic content}

The Folin-Ciocalteu reagent assay was used to determine the total phenolic content of extracts in accordance with the method followed by Lakshmi et al. (2018).

\subsubsection{Total flavonoid content}

The total flavonoid content of the spice extracts was determined by a method followed by Nayak et al. (2017) using quercetin as a standard. All determinations were performed in triplicate.

\section{Results and discussion}

The moisture of the drying sample is controlled by the heated air flow from the solar collector chamber to the drying chamber. the sample moisture content and temperature in drying chamber is monitored continuously, and if it is found to be less or greater than the set temperature or sample moisture content, the PI control tracks the stability by varying the air flow by air pump speed Hawlader et al. (2008). The three different air flow rates were entered into the collecting chamber. The maximum temperatures achieved with PI controlled pumps are $0.5,1$ and $2 \mathrm{~m} / \mathrm{s}$ are $63^{\circ} \mathrm{C}, 68^{\circ} \mathrm{C}$ and $65^{\circ} \mathrm{C}$, respectively, with almost similar ambient air temperature for all the velocities. At the end of two days of drying, i.e. $8 \mathrm{hrs} /$ day, the moisture content in the black turmeric in terms of weight loss is $110 \%, 68 \%$ and $85 \%$ for $0.5,1$ and $2 \mathrm{~m} / \mathrm{s}$, respectively. The moisture removal rate is fastest with the PI controlled air flow rate of $1 \mathrm{~m} / \mathrm{s}$, as compared with $0.5,2 \mathrm{~m} / \mathrm{s}$ and without pump as seen in Figure 2. The results were also in accordance with the Hegde et al. (2015).

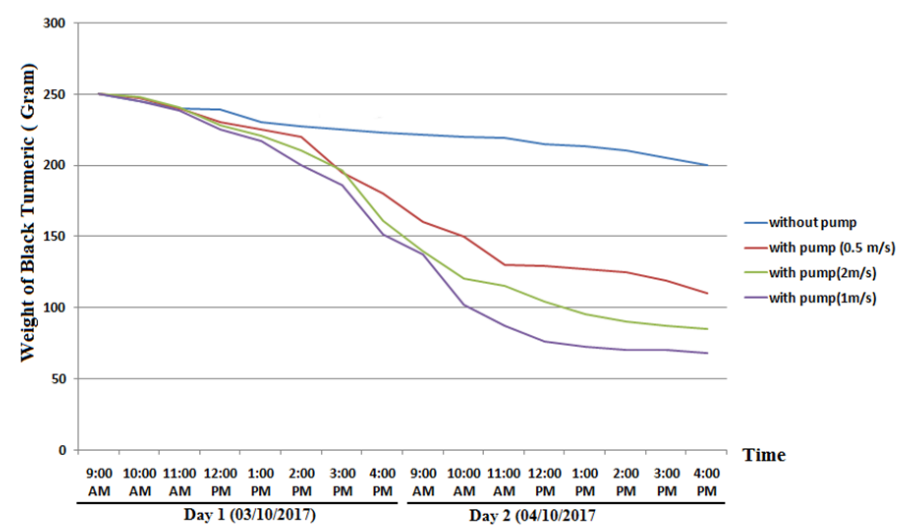

Figure 2. Variation of moisture content $(\mathrm{db}) \mathrm{kg}$ moisture $/ \mathrm{kg}$ dry wt. with drying time of black turmeric dried by different air flow rates

\subsection{Evaluation of model parameters}

The drying data obtained in the experiments were converted to dimensionless moisture ratio (MR). In order to determine the experimental moisture ratio as a function of drying time, five empirical models were used. The estimated parameters and the results of statistical analysis of these models were presented in Table 2. For all drying condition, the models showed the coefficient of determination $\left(\mathrm{R}^{2}\right)$ values in the range of 0.9367 to 0.9987 . It was indicated that many of the models could satisfactorily describe the drying kinetics of black turmeric slices. Among the thin layer drying models tested (Table 2), Modified page model indicated the highest $\mathrm{R}^{2}$ values with the lowest $\chi^{2}$ values.

\subsection{Quality analysis}

\subsubsection{Color of dried slices}

The three color parameters $\left(\mathrm{L}^{*}, \mathrm{a}^{*}, \mathrm{~b}^{*}\right)$ of fresh and dried samples are shown in Table 3 . The color of the airdried black turmeric was found to be dependent on the 
Table 2. Comparison of different drying models with drying coefficients (constants)

\begin{tabular}{cccc}
\hline Model & Model Constants & $\mathrm{R}^{2}$ & $\chi^{2}$ \\
\hline Lewis & $\mathrm{k}=0.01461$ & 0.9652 & 0.00182 \\
Page & $\mathrm{k}=0.00413, \mathrm{n}=1.28817$ & 0.9743 & 0.00065 \\
Modified Page & $\mathbf{k}=\mathbf{0 . 0 0 6 6 6}, \mathbf{n}=\mathbf{1 . 1 8 9 6 2}$ & $\mathbf{0 . 9 9 8 7}$ & $\mathbf{0 . 0 0 0 4 1}$ \\
Henderson and Pabis & $\mathrm{k}=0.00434, \mathrm{a}=0.77143$ & 0.9367 & 0.03652 \\
Two-term exponential & $\mathrm{a}=1.71397, \mathrm{k}=0.00983$ & 0.9543 & 0.00165 \\
\hline
\end{tabular}

Table 3. Quality analysis of black turmeric slices

\begin{tabular}{|c|c|c|c|c|c|c|c|c|c|c|c|c|}
\hline Slices & \multicolumn{4}{|c|}{ Fresh } & \multicolumn{4}{|c|}{ Solar dried } & \multicolumn{4}{|c|}{ Open sun-dried } \\
\hline Parameters & $\mathrm{L}^{*}$ & $a^{*}$ & $\mathrm{~b}^{*}$ & $\Delta \mathrm{E}^{*}$ & $\mathrm{~L}^{*}$ & $a^{*}$ & $\mathrm{~b}^{*}$ & $\Delta \mathrm{E}^{*}$ & $\mathrm{~L}^{*}$ & $a^{*}$ & $\mathrm{~b}^{*}$ & $\Delta \mathrm{E}^{*}$ \\
\hline Color & 44.22 & -1.55 & 14.58 & 46.32 & 40.01 & 1.94 & 13.88 & 42.33 & 34.15 & 1.25 & 11.99 & 33.12 \\
\hline $\begin{array}{l}\text { Antioxidant activity } \\
(\mu \text { mol of TE per g of } \\
\text { sample })\end{array}$ & & & & & & & & & & & & \\
\hline $\begin{array}{c}\text { Total phenolic } \\
\text { content } \\
\text { (mg GAE per g of } \\
\text { sample) } \\
\end{array}$ & & & & & & & & & & & & \\
\hline $\begin{array}{c}\text { Total flavonoid } \\
\text { content } \\
\text { (mg quercetin per } \mathrm{g} \\
\text { of sample) }\end{array}$ & & & & & & & & & & & 22 & \\
\hline
\end{tabular}

drying air methods. The measured parameters showed that the $\mathrm{L}^{*}$ and $\mathrm{b}^{*}$ value decreased with both the drying methods and $\mathrm{a}^{*}$ values was increased in solar-dried methods compare to open sun drying methods. The $\Delta \mathrm{E}^{*}$ values for fresh, solar dried and open sun-dried samples are $46.32,42.33$ and 33.12 . It is observed that the $\Delta \mathrm{E}^{*}$ value of the sample dried in solar drying methods is higher than that of the sample dried in open sun drying methods. The photographic views of the black turmeric taken before and after drying are shown in Figure 3.

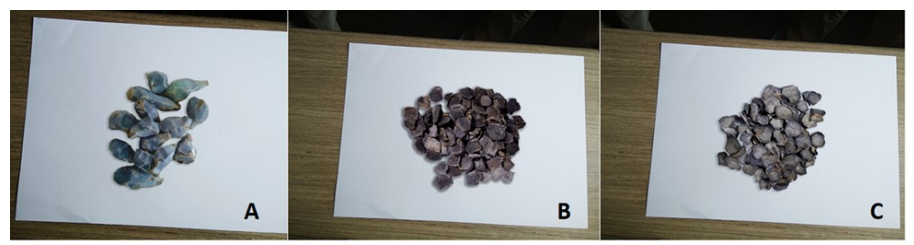

Figure 3. Photographic views of (A) fresh black turmeric (B) after Solar dried (C) after open sun-dried (Lakshmi et al., 2018)

\subsubsection{Effect of drying on antioxidant activity}

Antioxidant properties of fresh and dried samples (solar dryer and open sun drying) were investigated through DPPH Assay and their results are depicted in Table 3. The results indicated that the antioxidant activities of the samples were decreasing from fresh (46.62 $\mu \mathrm{mol}$ of TE per $\mathrm{g})$ to open sun-dried $(21.98 \mu$ mol of TE per g).

\subsubsection{Effect of drying on TPC and TFC}

The total phenolic contents of the powders were decreased from 20.11 to $7.27 \mathrm{mg}$ of GAE/g of extract. The phenolic content estimated in our results was probably responsible for the free radical-scavenging activity of black turmeric samples and, the levels of total flavonoids varied from 11.32 (fresh) to 6.22 (open sundried) $\mathrm{mg}$ of quercetin per gram of extract.

\section{Conclusion}

In the present work, performance analysis of indirect solar dryer has been carried out for drying of $25 \mathrm{~kg}$ black turmeric. The experimental results were further analyzed to find the best suitable thin layer drying kinetic model for solar dried samples. It was observed that the modified page model was found to be the best fit for solar dried samples. The results revealed that the optimized design and PI controller gives the significant improvements of the moisture removal in the proposed solar dryer design. It is also observed from the drying kinetics and quality analyses data, the newly developed low-cost solar dryer is definitely a better option for drying the high value medicinal agricultural products like black turmeric.

\section{References}

Akpinar, E.K. (2006). Mathematical modelling of thin layer drying process under open sun of some aromatic plants. Journal of Food Engineering, 77(4), 864-870.

https://doi.org/10.1016/

j.jfoodeng.2005.08.014

Arulmozhi, D.K., Sridhar, N., Veeranjaneyulu, A. and Arora, S.K. (2006). Preliminary mechanistic studies on the smooth muscle relaxant effect of hydroalcoholic extract of Curcuma caesia. Journal of Herbal Pharmacotherapy, 6(3-4), 117-124. 
https://doi.org/10.1080/J157v06n03_06

Babuskin, S., Babu, P.A.S., Sasikala, M., Sabina, K., Archana, G., Sivarajan, M. and Sukumar, M. (2014). Antimicrobial and antioxidant effects of spice extracts on the shelf life extension of raw chicken meat. International Journal of Food Microbiology, 171, 32-40. https://doi.org/10.1016/ j.ijfoodmicro.2013.11.011

Banerjee, A. and Nigam, S.S. (1976). Antifungal activity of the essential oil of Curcuma caesia Roxb. Indian Journal of Medical Research, 64(9), 1318-1321.

Basunia, M.A. and Abe, T. (2001). Thin-layer solar drying characteristics of rough rice under natural convection. Journal of Food Engineering, 47(4), 295 -301. https://doi.org/10.1016/S0260-8774(00)001333

Chavda, T.V. and Kumar, N. (2009). January. Solar dryers for high value agro prodcuts at Spreri. International Solar Food Processing Conference, 15

Dai, J.W., Rao, J.Q., Wang, D., Xie, L., Xiao, H.W., Liu, Y.H. and Gao, Z.J. (2015). Process-based drying temperature and humidity integration control enhances drying kinetics of apricot halves. Drying Technology, 33(3), 365-376. https:// doi.org/10.1080/07373937.2014.954667

Demir, V., Gunhan, T., Yagcioglu, A.K. and Degirmencioglu, A. (2004). Mathematical modelling and the determination of some quality parameters of air-dried bay leaves. Biosystems Engineering, 88(3), 325-335. https:// doi.org/10.1016/j.biosystemseng.2004.04.005

Devi, H.P., Mazumder, P.B. and Devi, L.P. (2015). Antioxidant and antimutagenic activity of Curcuma caesia Roxb. rhizome extracts. Toxicology Reports, 2, 423-428. https://doi.org/10.1016/ j.toxrep.2014.12.018

Ekechukwu, O.V. (1989). Experimental studies of integral-type natural-circulation solar-energy tropical crop dryers. United Kingdom: Cranfileld Institute of Technology, Ph.D. thesis.

Hägglund, T. (1996). An industrial dead-time compensating PI controller. Control Engineering Practice, 4(6), 749-756. https://doi.org/10.1016/0967 -0661(96)00065-2

Hawlader, M.N.A., Rahman, S.M.A. and Jahangeer, K.A. (2008). Performance of evaporator-collector and air collector in solar assisted heat pump dryer. Energy Conversion and Management, 49(6), 1612-1619.

https://doi.org/10.1016/ j.enconman.2007.12.001

Hegde, V.N., Hosur, V.S., Rathod, S.K., Harsoor, P.A. and Narayana, K.B. (2015). Design, fabrication and performance evaluation of solar dryer for banana. Energy, Sustainability and Society, 5(1), 23. https://doi.org/10.1186/s13705-015-0052-X

Kabganian, R., Julie Carrier, D. and Sokhansanj, S. (2002). Physical characteristics and drying rate of Echinacea root. Drying Technology, 20(3), 637-649. https://doi.org/10.1081/DRT-120002821

Kalra, C.L., Pruthi, J.S., Teotia, M.S., Raina, B.L., Sharma, B.R. and Nandpuri, K.S. (1983). Influence of variety on the quality of processed bitter gourd (Karela). Indian Food Packer, 37(4), 71-77.

Karmakar, I., Saha, P., Sarkar, N., Bhattacharya, S. and Haldar, P.K. (2011). Neuropharmacological assessment of Curcuma caesia rhizome in experimental animal models. Oriental Pharmacy and Experimental Medicine, 11(4), 251-255. https:// doi.org/10.1007/s13596-011-0032-4

Lakshmi, D.V.N., Muthukumar, P., Layek, A. and Nayak, P.K. (2018). Drying kinetics and quality analysis of black turmeric (Curcuma caesia) drying in a mixed mode forced convection solar dryer integrated with thermal energy storage. Renewable Energy, 120, 23-34. https://doi.org/10.1016/ j.renene.2017.12.053

Mangla, M., Shuaib, M., Jain, J. and Kashyap, M. (2010). In-vitro evaluation of antioxidant activity of Curcuma caesia Roxb. International Journal of Pharmaceutical Sciences and Research, 1, 98-102.

Maskan, A., Kaya, S. and Maskan, M. (2002). Hot air and sun drying of grape leather (pestil). Journal of Food Engineering, 54(1), 81-88. https:// doi.org/10.1016/S0260-8774(01)00188-1

Midilli, A. and Kucuk, H. (2003). Mathematical modeling of thin layer drying of pistachio by using solar energy. Energy Conversion and Management, 44(7), 1111-1122. https:// doi.org/10.1016/S0196-8904(02)00099-7

Midilli, A., Kucuk, H. and Yapar, Z. (2002). A new model for single-layer drying. Drying Technology, 20(7), 1503-1513. https://doi.org/10.1081/DRT120005864

Moreira, R., Chenlo, F., Chaguri, L. and Fernandes, C. (2008). Water absorption, texture, and color kinetics of air-dried chestnuts during rehydration. Journal of Food Engineering, 86(4), 584-594. https:// doi.org/10.1016/j.jfoodeng.2007.11.012

Nayak, P.K., Rayaguru, K. and Radha Krishnan, K. (2017). Quality comparison of elephant apple juices after high-pressure processing and thermal treatment. Journal of the Science of Food and Agriculture, 97(5), 1404-1411. https:// 
doi.org/10.1002/jsfa.7878

O'Dwyer, A. (2006). Handbook of PI and PID controller tuning rules 2nd ed. London: Imperial College Press. https://doi.org/10.1142/p424

Page, G.E. (1949). Factors Influencing the Maximum Rates of Air-Drying Shelled Corn in Thin layers. Indiana, US: Purdue University, MSc. Thesis

Pandey, A.K. and Chowdhury, A.R. (2003). Volatile constituents of the rhizome oil of Curcuma caesia Roxb. from central India. Flavour and Fragrance Journal, 18(5), 463-465. https://doi.org/10.1002/ ffj. 1255

Puglisi, L.J., Saltaren, R.J., Garcia, C. and Banfield, I.A. (2015). Robustness analysis of a PI controller for a hydraulic actuator. Control Engineering Practice, 43, 94-108. https://doi.org/10.1016/ j.conengprac.2015.06.010

Queiroz, A.J.D.M., Dantas, H.J., de Figueirêdo, R.M. and Melo, K.D.S. (2011). Solar drying of jack fruit almonds. Engenharia Agrícola, 31(6), 1150-1161. https://doi.org/10.1590/S0100-69162011000600012

Raisanen, W.R. (1979). System for measuring moisture content. U.S. Patent 4165633. Tempe, Arizona, US: Motorola Process Control Inc.

Rajamma, A.G., Bai, V. and Nambisan, B. (2012). Antioxidant and antibacterial activities of oleoresins isolated from nine Curcuma species. Phytopharmacology, 2(2), 312-317.

Rangana, S. (2005). Handbook of analysis and quality control. New Delhi, India: Tata McGraw Hill Publishing.

Rathore, N.S. and Panwar, N.L. (2011). Design and development of energy efficient solar tunnel dryer for industrial drying. Clean Technologies and Environmental Policy, 13(1),125-132. https:// doi.org/10.1007/s10098-010-0279-3

Saleh, A. and Badran, I. (2009). Modeling and experimental studies on a domestic solar dryer. Renewable Energy, 34(10), 2239-2245. https://doi.org/10.1016/j.renene.2009.03.001

Sarsavadia, P.N., Sawhney, R.L., Pangavhane, D.R. and Singh, S.P. (1999). Drying behaviour of brined onion slices. Journal of Food Engineering, 40(3), 219-226. https://doi.org/10.1016/S0260-8774(99)00058-8

Sengar, S.H. (2018). Evaluation of solar tunnel dryer for green leaves drying. Journal of Postharvest Technology, 6(2), 38-48.

Sharaf-Eldeen, Y.I., Blaisdell, J.L. and Hamdy, M.Y. (1980). A model for ear corn drying. Transactions of the ASAE, 5(4), 1261-1265. https:// doi.org/10.13031/2013.34757
Sukhatme, K. and Sukhatme, S.P. (1996). Solar energy: principles of thermal collection and storage. New Delhi, India: Tata McGraw-Hill Education.

Yurkevich, V.D. and Naidu, S.D. (2012). Educational Issues of PI-PID Controllers. Proceedings of the 9th IFAC Symposium Advances in Control Education, The International Federation of Automatic Control, Nizhny, Novgorod, Russia, June 19-21, 2012., p. 448 -453. Russia: The International Federation of Automatic Control.

Yaldiz, O., Ertekin, C. and Uzun, H.I. (2001). Mathematical modeling of thin layer solar drying of sultana grapes. Energy, 26(5), 457-465. https:// doi.org/10.1016/S0360-5442(01)00018-4 